THE JOURNAL OF

PHILOSOPHICAL ECONOMICS: REFLECTIONS ON ECONOMIC AND SOCIAL ISSUES

Volume X Issue 2 Spring $201 \%$

ISSN 1843-2298

Copyright note:

No part of these works may be reproduced in any form without permission from the publisher, except for the quotation of brief passages in criticism.
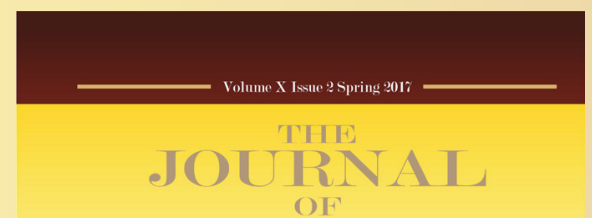

PHILOSOPHICAL E C O N O M I C S REFLECTIONS ON ECONOMIC AND SOCIAL ISSUES

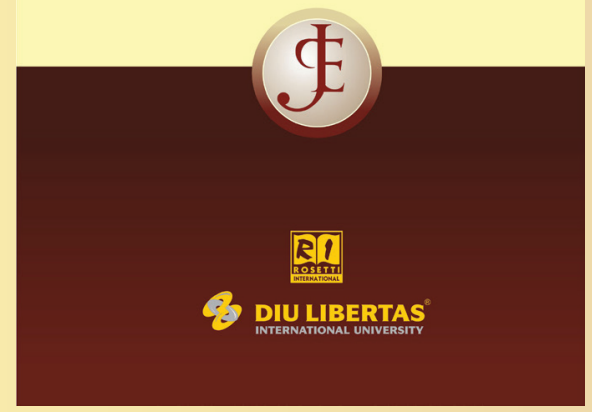

\title{
Economic theory in historical perspective
}

\section{Lefteris Tsoulfidis}

\section{DIU LIBERTAS}

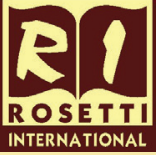




\title{
Economic theory in historical perspective
}

\section{Lefteris Tsonlfidis}

\begin{abstract}
On the methodological plain this paper outlines the conditions that contribute to the development of economic theories and it continues with an examination of the concrete circumstances that gave rise to modern neoclassical macroeconomic theories. The paper further claims that the current impasse in macroeconomics is indicative of the need for new directions in economic theory which becomes imperative in the long economic downturn that started in $200 \%$ and concludes by suggesting the need for a synthesis between the classical analysis and the theory of effective demand.
\end{abstract}

Keywords: classical approach, neoclassical theory, theory of value, effective demand, paradigm change

\section{Introduction}

In this paper, we attempt a brief and at the same time critical review of the salient features of each school of economic thought that withstood the test of time and is still fuelling with ideas and arguments for the conduct of economic policy. Furthermore, our interest focuses on the nature of economic theory and its future; inasmuch, as our analysis is conducted over very long stretches of time, whereby the phases of economic growth are followed by economic downturns in a long wave-like evolutionary pattern. 
This paper advances the claim that new economic theories might be the result of four non-mutually exclusive conditions: first, a new theory might be the product of the elaboration of an existing theory; second, it might be the outcome of systematic failures of the dominant theory to account for phenomena that it was designed to explain; third, it may lead to economic policy conclusions that are more relevant to dealing with current problems than the policies proposed by the existing and prevailing theory and last, but not least, a theory may prevail on the basis of the interests that it serves regardless of its ability to aid in prediction and the formulation of economic policy. When at least one of these conditions is met, then various adjustment processes might be activated that could lead to the further advancement of an existing theory, or even the replacement of a prevailing theory by an altogether new theory. In order to establish our claim, we combine economic history and the history of economic thought. The intuitive idea is that economic history constitutes the testing terrain for economic theory, thus enabling us to understand the past and current economic situations in a fuller and analytically more accurate way.

Furthermore, this combination of economic history and economic theory equips us with both the necessary data and analysis to confront current as well as future economic situations, at least, in a more prepared way.

The composition of the remainder of the paper is as follows: The second section deals with the core characteristics of the major economic approaches and the conditions that contribute to the development of economic theories. The third section continues with an examination of the concrete circumstances that gave rise to modern neoclassical macroeconomic theories. The fourth section makes some remarks about the elements for a new direction of economic theory and concludes with a need for a synthesis of the classical approach with the Keynesian theory of effective demand.

\section{Core characteristics of competing economic theories}

Economics as a scientific discipline was born out of observations concerning the movement of commodity market prices. Market prices were recognized as the main phenomenon whose deeper understanding would unlock and pave the way for the theorization of the workings of the economic system of generalized 
commodity exchange. Market prices, it was observed, are subjected to continuous fluctuations, whose superficial examination may suggest that they are purely stochastic, and, therefore, not amenable to generalization. A more careful examination, however, suggests that the actual prices of commodities are regulated by another set of more fundamental prices, the 'natural prices' which operate as centres of gravitation for market prices (Garegnani, 1976; Eatwell, 1983; Kurz and Salvadori, 1995; Tsoulfidis, 2008 and 2010).

More specifically, Adam Smith sought to discover the 'natural order' of economic life and for that, he was inspired by the movement of planets determined by the laws of gravity. Smith used this analogy to explain the movement of actual prices by the law of equal profitability which was supposed to hold in a particular set of hypothetical market prices which he called 'natural prices'. The term 'natural' signifies the fact that economic phenomena have their own internal dynamics, just like natural phenomena, and operate, as Francois Quesnay observed, in a way that is 'independent of men's will'. A salient feature of Smith's and the other classical economists' argument was the determination of natural prices by the labour time content of commodities and the explanation of profit as a form of surplus, over and above what is needed for the reproduction of labourers capacity to work on the one hand and of the productively consumed means of production on the other. In this determination some elements must be considered as moving more slowly with respect to others and, therefore, they can be treated parametrically; in this sense, the parameters or data of the classical analysis include the real wage, the output produced and the technology in use.

David Ricardo sought to discover the laws that determine the distribution of income by correcting and further elaborating various aspects of Smith's theory of value. In this context, we can also place Marx's (186\%-94) mature work in Capital, where he sets out 'to lay bare the law of motion of modern society' to which end the explanation of natural prices or prices of production was the first crucial step. By setting this analytical context classical economists established the scientific status of economics as they were the first to argue that capitalism gives rise to economic phenomena that display recurrent law-like regularities, which can be subjected to abstract theorization (Heilbroner, 1983). Consequently, economics became an inquiry that could generalize, and, 
therefore, theorize economic phenomena from their own market internal dynamics which can be discovered independently of ideology or religion.

The neoclassical approach, which emerged during the great depression of 18731896, continued to utilize the natural prices as the object of its inquiry. The difference from the classical approach being in the method of analysis which was based on an entirely different set of data comprising of the preferences of individuals, the size of the endowment and its distribution among individuals as well as the state of technology (Garegnani, 1976; Eatwell, 1983; Kurz and Salvadori, 1995). It took quite a long time for the neoclassical approach to become the established orthodoxy in economic theory. Some historians of economic thought characterize this succession as a silent non-revolutionary process that consolidated itself in the 1920s or 1930s (Blang, 1983; Hollander, 1985 and 1989).

No matter how long it took this process to fully unfold, its very purpose (stated or not) was to set aside the more realistic classical approach for its disturbing political implications, especially those emanating from the labour theory of value. The idea that the value of commodities is determined by their labour content was too challenging for a system that underwent through structural transformation. Industrial capitalists, up until the middle of the nineteenth century, were directly involved in the production process in their incessant pursuit of expanding profits as a purpose in itself and also the establishment of the new society as opposed to the traditional one. The labour theory of value contributed to the understanding of the source of profit as well as the source of incomes for the merchant and the landlord classes. As a result, the labour theory of value was the product of, and at the same time contributed to, the intellectual atmosphere for almost two centuries.

However, the growth of corporation and the subsequent concentration and centralization of capital that took place during the long depression of 1873-1896 changed the structure of the economy as well as the traditional role of the capitalist. The capitalist's direct involvement in the production process and other related activities was limited and the management of the newly created large-scale enterprises was transferred to a small group of owners or professionals (see also Chandler, 1977 and Schumpeter, 1942). As a consequence, 
the capitalist class was transformed, to a great extent, into a mere recipient of profit incomes by virtue of property rights in a way very similar to that of landlords. Naturally, under these new conditions, it became clear that profit income could not find justification in a labour content explanation of equilibrium prices, other than some form of exploitation of labour. This was already explicitly stated by Adam Smith

['T]he labourers and labouring cattle, therefore, employed in agriculture, not only occasion, like the workmen in manufactures, the reproduction of a value equal to their own consumption, and of the capital which employs them, together with its owner profits [. . .] (Wealth of Nations, p. 344).

This view has been part of the established economic ideas and so John S. Mill (1848) in his Principles - a text that continued to be popular until the turn of the nineteenth century - repeats, without further explanations that the

Cause of profits is that labour produces more than is required for its support.

And he concludes that profits arise exclusively from labour employed in production and not in circulation,

that profit arises, not from the incident of exchange, but from the productive power of labour; and the general profit of the country is always what the productive power of labour makes it, whether any exchange takes place or not. If there were no division of employments, there would be no buying or selling, but there would still be profit (J.S. Mill, Principles, 1848, pp. 416- 7 ).

Such views were regarded socially dangerous for the status quo and their dissemination should not be allowed due to their disturbing social implications. An additional reason for the dismissal of the labour theory of value has been the argument of the so-called Ricardian socialists (e.g., Robert Owen, William Thompson, Thomas Hodgskin, inter alia), who extended the labour theory of value to what they thought its logical and also normative conclusions (Rubin, 
1928; Hunt, 1992, inter alia). That is, the value of commodities is not only determined by the labour time that went into their production but should also be equal to their labour time. Consequently, as the value of a commodity is created by labour; the profits of capitalists and the rents of landlords are extracted from this value which naturally belongs to workers. These Ricardian socialists criticized the other classical economists, in particular, Ricardo for they accepted the exploitative nature of capitalism as natural and permanent, and therefore they did not see the need for social change. The approach of the Ricardian socialists contributed to anticapitalist sentiments since it implied that in essence there was no justification for the incomes of capitalists and landlords. John B. Clark, for example, reflecting the sentiment of his time illustrates very vividly the socially dangerous consequences that the labour theory of value may exert, he notes:

The indictment that hangs over society is that of 'exploiting labor.' 'Workmen' it is said, 'are regularly robbed of what they produce. This is done within the forms of law, and by the natural working of competition.' If this charge were proved, every right-minded man should become a socialist; and his zeal in transforming the industrial system would then measure and express his sense of justice. If we are to test the charge, however, we must enter the realm of production. (J.B. Clark, 1908, p. 4).

This is not to say that the first neoclassical economists were insensitive to social problems and that they did not try to propose solutions. For example, J. B. Clark favoured minimum wage legislation, in these cases where the real wage lied below the marginal product of labour; Walras was in favour of the nationalization of land and advocated that the rent which would be collected could be used to replace taxation; Wicksell was a radical who proposed a fairly revolutionary program of income redistribution from the rich to the poor, an idea that was reasoned out from the strict application of the principle of diminishing marginal utility of income. Furthermore, the first neoclassical economists argued for government intervention in the case of externalities and in the USA favoured antitrust legislation, while in Europe (especially in North Italy where the issue of uniting various smaller regional economies to a single nation state was urgent) there had been some progress in public finance. 
It is important to stress, however, that the first neoclassical economists were always under the spell of the classical economists. For example, the first antitrust legislation introduced at the end of the 19th century was not based on efficiency consideration such as the deadweight loss as one would expect from the strict application of the efficiency criteria of neoclassical theory, but rather from wealth-transfer concerns which were no different than those of the classical economists (Hunt, 1992, pp. 248-50). The same is true with regard to public finance issues, Schumpeter, for example, points out:
Smith's book on public finance [...] was to become the basis of all the nineteenth-century treatises on the subject until, mainly in Germany, the 'social' viewpoint - taxation as an instrument of reform - asserted itself (Schumpeter, 1954, p. 186).

If the purpose of economic theory is to explain the way in which the actual economy works, then there is no doubt that the classical approach was more relevant than the neoclassical one to the practice of business people, and, therefore, it was grounded on economic reality. For example, the distinction between productive and unproductive labour is part of the established prudent business practices, as these are reflected in the income statements of industrial corporations. More specifically, in these income statements the unproductive expenditures concoct with the gross profits (surplus); [1] the classical theory of competition is characterized by realism that is not found in the neoclassical perfect competition, which prima facie contradicts almost every aspect of real life competition (Shaikh, 1980; Eatwell, 1981, 2011 and Tsoulfidis, 2015). In fact, the idea of perfect competition did not arise from the historical observation of the way in which firms actually organize and compete with each other, but rather from the requirements of the neoclassical model of general equilibrium through which equilibrium prices are determined and are taken as given by individual agents.

The first neoclassical economists, i.e., the triad Jevons, Menger and Walras initially and subsequently Marshall, J. B. Clark and Böhm Bawerk, contributed to the creation of a new intellectual atmosphere in which the classical system was found to be unsatisfactory and its replacement by a theory that would legitimize property and emphasize the merits of an exchange economy became 
imperative although not necessarily urgent.[2] It is important to point out that these ideas were developed in the 'Victorian Era', which was a period of steady economic growth and so the demands for a realistic economic theory from policy makers were much more elastic. Whereas, in the period of depression of 18731896 both classical and neoclassical theories were in agreement with respect to no government intervention.

The task of the gradual replacement of classical theory by the neoclassical one was essentially accomplished by the architect of the neoclassical economics Alfred Marshall, who was very conscious of the status of the economic discipline of his time and the requirements for its future direction. He realized that more than a century of dominance of classical theory could not just be overthrown in a short period of time and that for the construction of a new theoretical perspective one needs to plan and above all to compromise with the hitherto dominant theory.[3] Some of the corrective compromises that he proposed included the following:

(i) The labour theory of value should be reduced to a cost of production theory, with Ricardo being credited as a forerunner of this 'cost of production' concept, his only weakness resting in that he was not fully attentive to an analysis of the demand side of the market (the other blade in Marshall's scissor). (ii) The distinction between productive and unproductive labour should be abandoned at some future and more appropriate timing (Marshall, 1890, p. 54).

(iii) The notion of competition as a dynamic process of rivalry between firms in their incessant struggle for survival should give way to the idea of perfect competition.

(iv) The classical economists notion of economies of scale which are the result of competition and division of labour evolving over historical time must be replaced by the static economies of scale, where time is purely conceptual (Marshall, 1890, chs. 9-13).

The lack of realism in this analysis was compensated for by transforming the neoclassical approach into the image of the natural sciences and especially physies. The extensive use of mathematies and also of neutral language that one finds in the writings of the major representatives of this approach served to underscore this purpose (Mirowski, 1984). Indeed, these efforts were highly 
successful in elevating neoclassical economics to a dominant position, albeit, at the expense of drifting further away from the real economies and the way they operate.

\section{An excursion to the 'dark age of macroeconomics' [4]}

In neoclassical economics, the determination of equilibrium prices takes place through the forces of demand and supply, while shortages or surpluses in the markets are eliminated through price variations. Naturally, these explanations did not prove to be convincing during the depression of the $1930 \mathrm{~s}$, as the slowdown in the level of economic activity was both deep and lasted until WWII. Under these circumstances, Keynes argued that the raison d'etre of unemployment is not the malfunctioning of the labour market, but the scarcity of effective demand. The latter does not depend on prices or a lack of saving, but on uncertainty and expectations, phenomena which can be hardly theorized. The scarcity of effective demand and the inability of the market system to generate effective demand to the amount required for the establishment of full employment of labour calls forth the activation of the political element, that is, of human intervention.

Thus the very simple fact that human intervention or the visible hand is necessary for a solution to economic problems was argued for the first time in a theoretical, and, therefore, convincing manner. The intellectual climate of the time was conducive to these ideas. In fact, in periods of depression, such as that of the 1930s, or even the depression that started in 2008, if not earlier, policymakers are prone to pay not only close attention to but also to implement new ideas, especially if the whole system is in jeopardy and the ideas promise successful results and are presented in a logically coherent and practical way. Keynes's theory, even in the 'rehabilitated' form that was given to it by Hicks and others in the so-called neoclassical synthesis, concentrated all these required characteristics and, what was even more crucial, its implementation delivered results, as one may judge by the overall economic performance during the period of the 'golden age of accumulation' that started after WWII and ended in the mid to late-1960s. Furthermore, post- WWII Keynesian economics provided the theoretical justification, and, therefore, created the necessity for a number of 
institutions promoting government spending thereby enhancing the process of capital accumulation. We can observe that economic theory during this period became more practically based, in the sense that it helped to solve real socioeconomic problems. Meanwhile, economics lost, at least partly, its purely scientific character and allowed the political element to play an important role in the management of economic affairs through the appropriate combination of fiscal and monetary policies.

As a consequence, there was widespread satisfaction with economics as a science and the policies emanating from its theoretical conclusions, since this was a period when high growth rates and low unemployment levels reined in an undisputed manner. By the mid-sixties, however, the situation gradually began to change, with growth rates slowing down, and unemployment levels starting to rise together with inflation. Both results were quite unexpected within the neoclassical synthesis version of the Keynesian paradigm, based upon the tradeoff between unemployment and inflation, as exemplified in the famous Phillips curve. The slowdown in economic activity that started in the mid-1960s and continued through the 1970s and into the 1980s led Keynesian economics into disrepute and decline. However, it is clear that this slowdown did not convert into a deep depression and so its results did not have the same destructive character as those of the 1930s depression. It is a commonly held view that the impact of the crisis in the 1970s and 1980s was so much different of that in 1930s because of the presence of institutions that prevented and in general ameliorated the harsh effects of this protracted slowdown.

Neoclassical economics, in its monetarist version, attributed the slowdown in the level of economic activity not to the internal defects of the market system but to external circumstances and in particular to government and its intervening role in the markets. These ideas found strong support by economists disappointed by the failure of Keynesians to explain the coexistence of high inflation and unemployment. By contrast, the monetarists claimed that they found an answer to the conundrum of stagflation through their idea of the expectationsaugmented Phillips curve and its associated natural rate of unemployment.

Actual unemployment is the result of households' choice insofar as they find the actual wage rate too low to motivate them to supply their labour services. This 
household decision, the monetarists argue, is further encouraged by governmental intervention in the labour markets. The solution to the problem of high unemployment is simply no government intervention and free operation of markets. However, the monetarist success and popularity were not to last for long, since the continuation of stagflation cast doubt to the monetarists' capacity to shed light on the causes of problems and furthermore their policy proposals of targeting the money supply was apparently an inadequate solution to dealing with stagflation. The failures of monetarism to come to terms with the new phenomena made room for the emergence of the variant of "new classical economics', which became the orthodoxy of the 1970s.[5]

New classical economics essentially merges the hypothesis of rational expectations with monetarism. The idea behind the rational expectations hypothesis is that if we do not consider the element of surprise, then whatever is to happen in the long run will also happen in the short run. The rational expectations hypothesis postulates that economic agents, on average, know the outcomes of the true model of the economy and thus do not waste any of their time searching for the monetarist long-run equilibrium situation; they simply transfer themselves virtually instantly there. Consequently, the systematic economic policy is ineffective in both the short and long run. In fact, there is no such dichotomy because the rational expectations hypothesis spirits away the notion of time. The attainment of equilibrium is the state where an economy naturally and instantaneously is led to unless there are exogenous shocks such as those emanating from technology, input prices and preferences or even from unanticipated government intervention.[6] The analyses of the new classical economists, like the monetarists before them, could neither provide satisfactory explanations nor policy prescriptions for the lasting slowdown in the level of economic activity and inflation. Paradoxically, the new classical economics managed to theorize the way out of the slowdown, by propounding the encouragement of the working of market mechanisms and of no government intervention.

The trough of this depression took place in the 1982 and it became the starting point for the emergence of the real business cycle approach, where the exogenous technological change (and not necessarily the money supply) becomes responsible for the exact phase of the economy. In this analysis, taken to its 
extremes, the actual stage of the economy is due to the optimization behaviour of the economic units and consequently, the recession or recovery phases are due to the optimal reaction of economic units to external shocks in the environment within which they operate. Recessions or recoveries are the results of voluntary reactions of households, which in the first case decide not to offer part of their labour services in order to offer them at more opportune times and in the second case find that their interests are served better by making their labour services available to economic activity. The results in both cases are optimal, which means that there is no reason for the government to intervene because it cannot further improve the current situation (Prescott, 1986, p. 21). In this perspective the economy is always at full capacity, therefore both capital and labour are continuously optimally utilized. Equilibrium in the labour markets is determined by the behaviour of inflation. Hence the acronym the nonaccelerating inflation rate of unemployment (NAIRU) can be seen as a characteristic example of the fetishism of economic categories within this approach, since the level of inflation rate is what 'decides' the characterization of actual unemployment as natural or excessive, since if the rate of inflation is steady then the economy will find itself in its natural, that is, long run equilibrium position regardless of the actual number of unemployed.

From the above, we may conclude that the monetarist, the new classical and especially the real business cycles approaches inevitably return to the tradition of neoclassical economics according to which economic theory is put on a par with the natural sciences and economic theory is, once again, deprived of its political element. The real trouble with these views and especially the popular, until very recently, real business cycles approach is the outbreak of depression, where they have no realistic policy proposals. A depression cannot be the optimal outcome unless individuals for unexplained reasons cease to behave rationally. Here is how one of the leading figures of this approach explains the dramatic events that took place in the world economy in 2008.

[P]eople got scared [...]. The press scared people. People running for office scared people. Bernanke scared people; Paulson scared people. [...] [Pleople began not to know what was going to happen. Then they stopped investing - by investing, I mean getting a new car or fixing up your house. And that led to the economy - it was depressed a bit that 
fourth quarter of last year [...] [ With] benign neglect the economy would have come roaring back quite quickly [...]. (Edward Prescott in an interview March 30, 2009, emphasis added)[7]

It goes without saying that the 'benign neglect' as the economic policy proposal to deal with the first great depression of the 21st century is in line with the identification of the cause of depression, that is, 'scared people! Meanwhile, the real business cycle approach together with the new classical economics and monetarism during the last three decades created an intellectual atmosphere against government intervention and for free market and in so doing the Keynesian safety networks - that were created during the 'golden age of accumulation'- have been truncated in the 'silent depression' of the 1980s. As these three approaches have no policies to propose, other than the general fixes that have been tried in recessions, it follows that the pressure for an active government role will be widespread.

These considerations contributed to the increasing popularity of the New Keynesian approach according to which we should move to less restrictive economic models. A common theme of this approach is the continuous effort to provide microfoundations to macroeconomics. It is important to point out that the essential component of the microfoundations is the neoclassical theory of competition in its monopolistic form together with various rigidities across markets which make government intervention especially in the field of monetary policy effective once again. This approach in its triumphant comeback can also make use of rational expectations as an auxiliary hypothesis for the faster attainment of the New Keynesian equilibrium. The idea is that if the New Keynesian model is the true model of the economy, then, naturally, economic agents will attain its results without wasting any of their time in nonequilibrium situations. Furthermore, there is an ongoing discussion about the creation of a new neoclassical synthesis, which will combine all the progress that has been achieved in neoclassical macroeconomics.

As a result of these efforts, economists aspired by the different variants of neoclassical approach claim that they have reached a consensus and the approach naturally came to be known as New Consensus Macroeconomics, where the word consensus is used rather as a euphemism for the current state of 
macroeconomics. The consensus for the core model without trade, [8] refers to the IS curve which is derived through the use of the output gap determined by previous and expected output gaps as well as the difference between nominal interest rate and expected inflation; the Phillips curve, where current inflation is determined by past and expected inflation as well as the current output gap; and, finally, the Taylor rule, where the current interest rate, the major (monetary) policy tool nowadays is determined by the output gap, the differences between current and target inflation rate as well as the normal interest rate. To our view, this model is not far away from the neoclassical approach according to which the economy can come back to its growth path with some fixes and in these fixes, the rate of interest becomes the crucial variable.[9] Besides the too little, too late' problem of this approach, the issue of the determination of the normal interest rate, the most crucial of the variables of this approach is of dubious theoretical validity. And the use of returns on long-term government bonds as a proxy for the natural interest rate is questionable even among the users of this approach. Furthermore, as the interest rates of Central Banks have fallen to zero or near zero levels, one may question the validity of policies of controlling interest rate on practical grounds. It seems that the liquidity trap has not only returned but the interest rate is in such a low level that neither Keynes nor Hicks would have ever imagined.

This discussion about the difference between the interest rate from its normal level brings into the analysis of the concept of NAIRI- the acronym stands for the non-accelerating inflation rate of interest, and its difference from the NAIRU or the less well-known NAICU, where CU stands for capacity utilization, the emphasis is placed on the interest rate as the major policy tool. It is important to stress at this point that in any acronym used, the primary interest of policymakers is on the variable called inflation rate! The inflation rate in all cases 'decides' whether there is unemployment in the economy, reserve capacity or disequilibrium interest rates. Hence, we observe that in all major macroeconomic theories there is a fetishization of the category inflation rate which is accompanied by an apotheosis of empiricism and a poverty of theory.

As current macroeconomic theories are based on neoclassical microeconomic foundations the whole construction is therefore unstable and although efforts for improvements may continue, since the substance from which this synthesis is 
made of, that is, the neoclassical microeconomics and also the conception of competition not as a process but rather as an end state make these

macroeconomic approaches questionable and as they fail to provide satisfactory solutions make the macroeconomies to stay in conditions of flux a condition that remains there since the end of the golden stage of accumulation in the late 1960s. Finally, this monetary policy exercise inspired by the new consensus macroeconomics may only be meaningful when the inflation and interest rates are at low levels. Furthermore, the economy must be growing at a rather healthy rate, because in a sharp downturn, such as the one that began in $200 \%$, it is very unlikely that a monetary policy of changing the interest rates by fractions of percentage points will have any perceptible effect on the aggregate economic variables. Fiscal policy would become imperative and with that, the consensus in new consensus macroeconomics would be called to question. Paraphrasing Goodhart's law, we may say that 'any observed macroeconomic concession will tend to collapse once pressure is placed on it for control purposes. For example, we know that in the mid-1960s the consensus was 'we are all Keynesians now' [10] but a few years later macroeconomics became a deeply divided discipline. The new consensus macroeconomic model also has difficulties with the measurement of capacity output and the expected prices even under normal growth rates. The model becomes questionable in inflationary or deflationary conditions.

\section{Summary and concluding remarks}

We argued that the purpose of economic theories is to lay bare the laws of motion of the economy and to determine the limits of variation of economic variables so as to provide guidelines for possible political intervention. We argued that the classical theory, as this has been restated through a linear model of production with givens the real wage, the level of output and the state of technology, is based on solid theoretical foundations and in this sense has certain advantages over the neoclassical theory. Having to judge between models, we share Samuelson's view according to which

it is better to have a model with inexact foundations that gives you a good grip to handle reality than to wait for better foundations or to 
continue to use a model with good foundations that is not usefully relevant to explain the phenomena that we have to explain (Samuelson 1988, p. 295).

With this suggestion in mind, the classical model as defined above concentrates the required properties of a theory that reveals the basic trends of the capitalist system and, at the same time, takes into account the specific institutional arrangements. This is clear for instance in Smith's or Ricardo's labour theory of value in a primitive society, which is modified to accommodate the concrete circumstances of capitalism. The same is true with Marx, whose 'laws of motion' work more precisely in conditions of advanced capitalism. In this sense, the classical approach is preferred to the neoclassical one. This superiority, however, of a theoretical level must materialize in a concrete analysis that can interpret the phenomena and predict with relative accuracy the results of specific economic policies (Tsoulfidis, 2008; Mariolis and Tsoulfidis 2009; 2016). Otherwise, the classical approach maintains its advantages over competing theories only for the eyes of its supporters without having any further implications.

In this direction, classical analysis should be integrated with the theory of effective demand. The idea is that this theory leaves the question of integration of institutional elements with the classical economic theory open. Keynes was very conscious of these elements since his theory operates under the institutional set up of advanced capitalism with already developed money and capital markets as well as governments capable of understanding the circumstances and effectively intervening in the direction of attainment of desired goals.

Neoclassical theory, by contrast, is mostly a-historical in its approach for it tends to conceptualize the market independently of institutions. In the perfect competition model, which constitutes the quintessence of the neoclassical structure, institutions are generally viewed as a kind of friction to the normal operation of the markets. The truth is that markets would simply perish without the existence of governments and the outer institutional shell. The recent new institutional economics that purports to account for the role of institutions continues to accept the methodological individualism and the a-historical 
conceptualization of the standard neoclassical theory together with the exact same set of data.

The difference is that while the old neoclassical theory with the general equilibrium model and the assumption of perfect competition gives rise to optimal results in terms of prices and the welfare of society at the expense of realism, the new institutional economics, on the other hand, makes an effort to theorize the real world characteristies of actual competition and to account for all possible imperfections. The trouble with such efforts is that the models employed turn out to be ad hoc meaning that for each phenomenon they study they must use a separate model. Consequently, general equilibrium and the associated with it models become intractable and they are open to any possible outcome.[11]

If we can visualize a direction for the future of economic theory then this would lie in the creative synthesis of the classical research program of economic analysis with Keynes's principle of effective demand. There has been much discussion about the possibility of providing such microfoundations for the classical theory of value and distribution starting with the works of Kalecki already in the late thirties who made an effort, on the one hand, to dispense with the marginal productivity theory of income distribution and, on the other hand, to put the principle of effective demand in a classical perspective (Kalecki, 1939). Subsequently, the works of post-Keynesian and especially neoricardian economists made valiant efforts to integrate the classical theory of value with the theory of effective demand with much frustration and little progress (Eatwell, 1983). Such a synthesis, in our opinion, cannot be successful insofar as it merely juxtaposes the classical theory and the principle of effective demand'. In our view for a synthesis to be fruitful it should intertwine the classical theory of value and the 'principle of effective demand' in such a way so as to expose the limitations of Keynes's ideas, where there is by and large an exaggeration of the financial autonomy of capital and brings into the analysis an essentially deus ex machina in the form of 'animal spirits' or 'expectations'. The deficiency of effective demand must be seen more in a classical and Marxian framework, where effective demand is cyclical and structural emanating from within the elemental process of capital accumulation. In such a conceptualization one might be able to set up the boundaries within which the 
effective demand exerts its effects on the economy and to use these boundaries to further develop the theory of capital accumulation.

The need today for such a synthesis has become particularly urgent. The reason is that so long as the economies are in their expansionary state, as they have been from the early-1980s until the outbreak of economic crisis in 2008, the problem of lack of an adequate theory does not manifest itself all that seriously and we can afford the luxury of having many competing paradigms in a neverending contest. But when economies enter their long downward phase, then the need for an adequate theory becomes more and more urgent since in the new situation the safety networks that were in place during the downward phase of the 1970s and early 1980s no longer exist to contain, as they did back then, to a great extent, the destructive effects of the depression. The need for such a theory certainly exists and as the problems of high unemployment, rising income inequalities and widespread poverty, loom gravely on a global scale, the neoclassical theory and its various strands become more-and-more 'scientific' and dismissive of the harsh reality hypothesizing perfect markets and perfect information, rational expectations and optimality, desired unemployment and inefficient government intervention. Under these circumstances, the need to explain these phenomena and their causes becomes imperative and the classical economies will become particularly important in both understanding the causes of these phenomena and proposing policies that would strengthen the safety mechanisms that were in place in the 1970s and 1980s and also propose new ones that can be derived from such an economic analysis.

\section{Endnotes}

[1] In the gross profits are included, among others, the salaries of the administrative personnel, as well as the materials and depreciation, related to administration activities. By contrast, the wages of workers in production, as well as the materials and depreciation of fixed capital employed in production are part of business costs.

[2] The emphasis on the exchange does not mean that neoclassical economists undermined production, it only means that even production is viewed as a 
process of indirect exchange, where consumers demand the services of the factors of production not directly but only through their demand for consumer goods.

[3] The motto of his (1890) book natura non facit saltum is quite revealing of Marshall's conservative approach.

[4] The characterization 'dark age' has been coined by Paul Krugman to indicate that in the 'dark ages' people forgot the ideas of Greeks and Romans, while in the 'dark age of macroeconmics' economists have lost an appreciation of the ideas developed in the 1930s and especially Keynes's theory of effective demand.

[5] It was hard, for policy makers, to accept the simplistic nature of monetarist 'policy prescriptions' which called forth for no government intervention and growth of money supply at a level approximately equal to the long-term growth rate of GDP. But monetarism had an enormous influence on governments and set the tone for the era of the so-called neoliberalism that swept the globe since the 1980s.

[6] It is important to point out that the acceptance of a particular theory depends, to a certain extent, on the interests that it serves, something that is at least partially independent of the ability of a theory to aid in prediction and the formulation of economic policy. In this context, one should place the supply-side economics in the early 1980s, which sought to limit the role of the state. This was much more suited to the needs of capital in the age of globalization, when domestic demand becomes less important as a source of economic growth. It goes without saying that such theories descent for a short time period and then they lose completely their reputation.

[7] The interview was taken by Tom Keene of Bloomberg's On the Economy.

[8] For an expanded version of the model see the critical presentation by Arestis (2009).

[9] The targeting of interest rate is an indirect recognition from the part of monetary authorities of the endogenous character of the money supply. 
[10] This statement is attributed to Milton Friedman by the Time magazine (December, 1965) although in the next issue of the magazine Friedman complained that he was misquoted and that what he really said was that in one sense, we are all Keynesians now; in another, nobody is any longer a Keynesian'. From this Delphic statement one thing is certain: the characterisation 'Keynesian' was received favourably by the majority of economists at the time. The same characterisation would not have been so favourably received in the early 1980s.

[11] For a critique of institutional economies from a Marxian perspective see Ankarloo and Palermo (2004).

\section{Acknowledgments}

I am indebted to Sean Homer, Theodore Mariolis, Panagiotis Michaelides, Aris Papageorgiou, Nicholas Theocarakis, Persefoni Tsaliki and other commentators of previous versions of the paper presented in various conferences.

\section{References}

Ankarloo, D. and Palermo, G. (2004), 'Anti-Williamson: a marxian critique of new institutional economics', Cambridge Jonrnal of Economics, 28, 413-429.

Arestis, P. (2009), New Consensus Macroeconomics and Keynesian critique. Mimeo. New York: Levy Institute.

Blaug, M. (1983), Economic Theory in Retrospect, Cambridge: Cambridge University Press.

Chandler, A. (1977), The Visible Hand, Cambridge Mass.: The Belknap Press of Harvard University Press.

Clark, J. B. (1908), The Distribution of Wealth. A Theory of Wages, Interest and Profits, London: MacMillan. 
Eatwell, J. (1981), 'Competition', in Bradley, I. and Howard, M. (eds.), Classical and Marxian Political Economy: Essays in Memory of Ronald Meek, London: Macmillan, pp 203-228.

Eatwell, J. (1983), 'Theories of value, output and employment', in Eatwell and Milgate (eds.), Keynes's Economics and the Theory of Value and Distribution, New York: Oxford University Press, pp 21-69.

Garegnani, P. (1976), 'On a change in the notion of equilibrium in recent work on value and distribution', in Brown M., Sato K. and Zarembka P. (eds), Essays in Modern Capital Theory, Amsterdam: North Holland, pp 25-45.

Heilbroner, R. (1983), 'The problem of value in the constitution of economic thought, Social Research, 50, 253-27\%.

Hollander, S. (1985), 'On the substantive identity of the ricardian and neoclassical conceptions of economic organization: The French connection in British classicism', in Caravale, G. (ed.), The Legacy of Ricardo, New York: Basil Blackwell, pp 22-45.

Hollander, S. (1989), 'On P. Mirowski's "physies and the marginal revolution”, Cambridge Journal of Economics, 13, 459-70.

Hunt, E. (1992), History of Economic Thonght, New York: Harper \& Collins.

Hunt, S. (2000), A General Theory of Competition, Resources, Competences, Productivity, Economic Growth, London: Sage Publications.

Kalecki, M. (1939), Essays in the Theory of Economic Fluctuations, London: Allen and Unwin.

Kurz, H., and Salvadori, N. (1995), Theory of Production, Cambridge: Cambridge University Press.

Marshall, A. (1890), Principles of Economics, London: MacMillan (8th Edition, 1969). 
Lefteris Tsoulfidis (2017), 'Economic theory in historical perspective', The Journal of Philosophical Economics: Reflections on Economic and Social Issues, X: 2, 102-124

Mariolis, T. and Tsoulfidis, L. (2009), 'Decomposing the changes in production prices into "capital-intensity" and "price" effects: Theory and evidence from the Chinese economy', Contributions to Political Economy, 28, 1-22.

Mariolis T. and Tsoulfidis, L. (2016), Modern Classical Theory and Reality: A Spectral Analysis of the Theory of Value and Distribution, Tokyo: Springer.

Marx, K. (1967, [1867-94]), Capital 3 vols, New York, International Publishers, $196 \%$.

Mill, J. S. (1848), Principles of Political Economy, Fairfield, NJ: Augustus M. Kelley (1976).

Mirowski, P. (1984), 'Physies and the Marshallian revolution', Cambridge Journal of Economics, 8, 361-79.

Prescott, E. (1986), 'Theory ahead of business cycles measurement', Federal Reserve Bank of Minneapolis, Quarterly Review, 10, 9-21.

Rubin, I. (1928), A History of Economic Thought, London: Ink Links (1979).

Samuelson, P. (1988), 'What would Keynes have thought of rational expectations? Comments on Axel Leijonhfvud', Collected Scientific Papers of Paul Samuelson, vol. 5, Cambridge, Massachusetts: The MIT Press, pp 291-300.

Schumpeter, J. (1942), Capitalism, Socialism and Democracy. New York: Harper and Row.

Schumpeter, J. (1954), History of Economic Analysis, New York: Oxford University Press.

Shaikh, A. (1980), 'Marxian competition versus perfect competition: Further comments on the so-called choice of technique', Cambridge Journal of Economics, 4, 75-83. 
Shaikh, A. (2016), Capitalism: Competition, Conflict, Crises, Oxford, Oxford University Press.

Tsoulfidis, L. (2008), 'Price-value deviations: further evidence from inputoutput data of Japan', International Review of Applied Economics, 22, 707-724.

Tsoulfidis, L. (2010), Competing Schools of Economic Thought, Heidelberg: Springer.

Tsoulfidis, L. (2015). 'Contending conceptions of competition and the role of regulating capital', Panoeconomicus, 62(1), 15-31.

Lefteris Tsoulfidis is Professor of Economics and Director of the Laboratory of Economic and Social Research (LESR), Department of Economics, University of Macedonia, Thessaloniki (Greece) (Int@uom.edu.gr). 